\title{
Antioxidant activity of shelf stable herbal seasoning incorporated with Pleurotus sajor-caju (oyster mushroom) powder
}

\author{
${ }^{1}$ Saiful Bahri, S. and ${ }^{2}$ Wan Rosli, W.I. \\ ${ }^{1}$ Food Science and Technology Research Centre, MARDI, 43400, UPM Serdang, Selangor Darul Ehsan, \\ Malaysia \\ ${ }^{2}$ Nutrition Programme, School of Health Sciences, Universiti Sains Malaysia, 16150 Kubang \\ Kerian, Kelantan Darul Naim, Malaysia
}

\author{
Article history: \\ Received: 5 July 2020 \\ Received in revised form: 23 \\ July 2020 \\ Accepted: 16 August 2020 \\ Available Online: 8 \\ November 2020
}

Keywords:

Antioxidant activity,

Herbal seasoning,

Pleurotus sajor-caju,

Total phenolic content,

Storage study

DOI:

https://doi.org/10.26656/fr.2017.5(1).330

\begin{abstract}
Pleurotus sajor-caju (oyster mushroom) has been consumed by people worldwide and they are known to produce different kinds of bioactive compounds. In this study, the methanolic extracts of herbal seasoning (HS) incorporated with Pleurotus sajor-caju (PSC) powder were evaluated for their antioxidant activity. A total of six different formulations with different levels of PSC powder at $0 \%$ (A), 20\% (B), 40\% (C), 60\% (D), $80 \%$ (E) and $100 \%$ (F) to substitute coconut milk powder (CMP) were used in this study. The products were evaluated at the 0 -month and 6-month of storage. HS (F) recorded the highest TPC (total polyphenol content) $(1823.84 \pm 0.84 \mathrm{mg}$ GAE/g), ABTS (2,2-azino-bis3-ethylbenzothiazoline-6-sulphonic acid) (71\%) and FRAP (Ferric Reducing Antioxidant Power) assays (60.52 mg AAE/g) at 0 month of the storage study. At the 6-month of storage study, the highest TPC, ABTS and FRAP assay were recorded in HS(F) $(1539.23 \pm 0.61 \mathrm{mg} \mathrm{GAE} / \mathrm{g}),(59 \%)$ and $(27.51 \mathrm{mg} \mathrm{AAE} / \mathrm{g})$, respectively. HS(A), the control treatment recorded the lowest TPC, ABTS and FRAP assay at the 6-month of the storage study. The addition of PSC powder to replace CMP may influence the presence of bioactive compounds in HS. The reduction of antioxidant after 6 months of storage might be due to the instability of other antioxidant compounds such as carotenoids and phenols. In conclusion, after the 6-month of the storage study, this edible mushrooms still exert some antioxidative capacities thus potentially being expended as a natural antioxidant in thermally processed food products.
\end{abstract}

\section{Introduction}

Mushrooms have been consumed by people worldwide for their nutritional, therapeutic and culinary values. Many genera of mushrooms are edible and ideal sources of nutritional ingredients since they are low fat and cholesterol content, high protein, rich in minerals, polysaccharides and polyphenols (Barros et al., 2008). In nature, about 150000 different types of mushrooms are available but only $10 \%$ is known and designated (Wasser, 2010). Mushrooms have been known as a part of the human diet in many regions of the world for centuries due to special organoleptic characteristic as well as the nutritional values (Wang and $\mathrm{Xu}, 2014$ ). They also possess secondary metabolites which include phenolic compounds like terpenes, polyketides and steroids that responsible for pharmacological properties, nutritional and health applications to the consumers (Turkoglu et al., 2007; Mahae and Chaiseri, 2009).
Antioxidants are capable to scavenge free radicals and also retarding the process of lipid peroxidation in food. Thus, the shelf life will be longer. Moreover, the consumption of antioxidant-rich foods benefits the diverse physiological to the target consumers such as protection against diseases related to oxidative stress like coronary heart diseases and cancer (Halliwell, 1999).

The consumption of diets rich in antioxidants could be a possible remedy to the oxidative damage of cellular components. Food that considers high in antioxidant activity possess compounds such as phenolics and flavonoids. These compounds have been reported to possessed antioxidant, anticancer, antimicrobial and antiradical properties (Silveira et al., 2015). Edible mushrooms are able to scavenge free radicals by unpaired electron due to their excellent antioxidant and consisting of different polyphenolic compounds. Other useful applications of edible as well non-edible 
mushrooms have been researched in food, cosmetics and also in disease treatments as the results of their valuable antioxidant properties. On the other side, the incorporation of food high in antioxidants commonly applied to the food products containing lipids and its associated foods to lengthen the shelf life of the products (Olajire and Azeez, 2011). Furthermore, ready to eat (RTE) and ready to cook (RTC) food products show increasing demands from the consumers' point of view. They are easy to prepare with a simple method of preparation.

Due to the technological development in food processing and the demands of consumers for fresh, safe and high-quality foods, the estimation of shelf life date has become more important. The shelf life of food basically is determined by their changes in sensory attributes of the products (Charalambous, 1993). Generally, the thermal treatments are given to the products basically contribute to the reduction of antioxidant capacity but some findings reported that processing may even improve quality due to an increase in the bioavailability of some antioxidants (Klein and Kurilich, 2000; Kaur and Kapoor, 2001) Although antioxidant defence and repair systems are available in humans and other organisms to protect them against oxidative damage, these systems are insufficient to totally prevent the damage (Mau et al., 2002). Furthermore, the information regarding the antioxidative value of mushrooms in bottle packaging is generally limited compared to canning. Bottling techniques are useful since the products can be hot filling which is extremely important to reach a high level of food safety and to limit the contamination in the filling room in ensuring a safe filling technology. On the other hand, the technique can extend the shelf stability of the products (Bottani et al., 2011; Berk, 2013).

Since the search for cheaper and more abundant natural sources of antioxidants is increasing all over the world, studies are needed to investigate the ability of PSC powder act as antioxidative properties. Pleurotus sajor-caju is chosen more than other Pleurotus species in the aspect of delicious taste, high in protein, low-fat content and rich in minerals (calcium, phosphorus, iron) and vitamins (thiamin, riboflavin and niacin) (Manzi et al., 1999; Kurtzman, 2005; Caglarirmak, 2007). Recently, it was discovered that oyster mushroom powder has improved some antioxidant content of butter biscuit (Wan Rosli et al., 2012) and rice-based products (Aishah and Wan Rosli, 2013). Many findings available of the composition and antioxidative values of fresh mushrooms but they are scanty study focusing on the antioxidative properties of the products during storage.
In this study, we examined the different ratios of PSC powder emphasizing on total polyphenol content and the scavenging activities of the developed products stored for 0 and 6 months. The findings from the present study are needed for future investigation especially the determination of the functional properties and to improvise the concentration of the PSC powder extract in other food products.

\section{Materials and methods}

\subsection{Sample preparation and product development}

The dried Pleurotus sajor-caju (PSC) (oyster mushroom) were supplied by AnjaadSdn. Bhd., Malacca, Malaysia which underwent a drying technique under Biodehydration $^{\mathrm{TM}}$ system. The dried PSC were screened for defects and grounded using food grinder (National MX 895M). The PSC powder was then kept in an appropriate plastic bag for further analysis and processing. There were six samples of herbal seasoning (HS) which were formulated with PSC powder at different percentage namely, $0 \%$ (A-control), or 20\%(B), or $40 \%(\mathrm{C})$, or $60 \%(\mathrm{D})$, or $80 \%(\mathrm{E})$ or $100 \%(\mathrm{~F})$ to replace coconut milk powder (CMP). The ingredients used were shown in Table 1. HS were prepared by incorporating the locally available herbs, blend of spices, PSC powder and CMP. Composite powders and other dry ingredients were mixed with culinary herbs in a jacketed kettle before water was added. Citric acid was used to ensure the $\mathrm{pH}$ to be less than 4.5 and the mixture was then continuing to heat until boiling. This is followed by hot filling procedure into glass bottles of $230 \mathrm{~g}$ followed by second pasteurization in boiling water until the internal temperature of the product reaches $93^{\circ} \mathrm{C}$. The finished products were then kept at room temperature for further analysis.

\subsection{Standards and reagents}

All the chemicals and reagents were of analytical grade purity. Folin-Ciocalteu reagent and gallic acid were purchased from Sigma-Aldrich $(\mathrm{GmbH}$, Sternheim, Germany). 2,2'-azinobis (3-ethylbenzthiazoline)-6sulfonic acid $\left(\mathrm{ABTS}^{+}\right)$, ascorbic acid, iron (III) chloride anhydrous $\left(\mathrm{FeCl}_{3}\right)$ and other chemicals were purchased from Merck (Darmstadt, Germany). Distilled and deionized water was used throughout the experiment.

\subsection{Preparation of extracts}

Total polyphenols and antioxidative capacity were determined following the method of Perez-Jimenez et al. (2008). About $10 \mathrm{~g}$ of HS was extracted with $40 \mathrm{~mL}$ of methanol: water $(50: 50, \mathrm{v} / \mathrm{v} ; \mathrm{pH} 2.0)$ at room temperature using an ultra-speed homogenizer for 5 
Table 1. Raw ingredients used in HS enriched with PSC powder

\begin{tabular}{|c|c|c|c|c|c|c|}
\hline \multirow{2}{*}{ Ingredients $(\%)$} & \multicolumn{6}{|c|}{ PSC powder level $(\%)$} \\
\hline & 0 & 20 & 40 & 60 & 80 & 100 \\
\hline Pleurotus sajor-caju (PSC) powder & 0 & 4 & 8 & 12 & 16 & 20 \\
\hline Coconut milk powder & 20 & 16 & 12 & 8 & 4 & 0 \\
\hline Dried chili & 1.6 & 1.6 & 1.6 & 1.6 & 1.6 & 1.6 \\
\hline Fresh turmeric & 1.1 & 1.1 & 1.1 & 1.1 & 1.1 & 1.1 \\
\hline Ginger & 1.7 & 1.7 & 1.7 & 1.7 & 1.7 & 1.7 \\
\hline Galangal & 0.8 & 0.8 & 0.8 & 0.8 & 0.8 & 0.8 \\
\hline Onion & 20.4 & 20.4 & 20.4 & 20.4 & 20.4 & 20.4 \\
\hline Shallot & 9.4 & 9.4 & 9.4 & 9.4 & 9.4 & 9.4 \\
\hline Garlic & 2.4 & 2.4 & 2.4 & 2.4 & 2.4 & 2.4 \\
\hline Cumin powder & 0.8 & 0.8 & 0.8 & 0.8 & 0.8 & 0.8 \\
\hline Fennel powder & 0.8 & 0.8 & 0.8 & 0.8 & 0.8 & 0.8 \\
\hline Coriander & 1.6 & 1.6 & 1.6 & 1.6 & 1.6 & 1.6 \\
\hline Crude coconut & 6.3 & 6.3 & 6.3 & 6.3 & 6.3 & 6.3 \\
\hline Dried lime & 0.4 & 0.4 & 0.4 & 0.4 & 0.4 & 0.4 \\
\hline Salt & 2.4 & 2.4 & 2.4 & 2.4 & 2.4 & 2.4 \\
\hline Black pepper & 0.4 & 0.4 & 0.4 & 0.4 & 0.4 & 0.4 \\
\hline Lemon grass & 1.6 & 1.6 & 1.6 & 1.6 & 1.6 & 1.6 \\
\hline Water & 26.7 & 26.7 & 26.7 & 26.7 & 26.7 & 26.7 \\
\hline Citric acid & 0.4 & 0.4 & 0.4 & 0.4 & 0.4 & 0.4 \\
\hline Sugar & 1.6 & 1.6 & 1.6 & 1.6 & 1.6 & 1.6 \\
\hline $\begin{array}{l}\text { 'Bunga Kantan' } \\
\text { (Etlingera elatior) }\end{array}$ & 10 & 10 & 10 & 10 & 10 & 10 \\
\hline $\begin{array}{l}\text { Turmeric leaves } \\
(\text { Curcuma longa } \mathrm{L})\end{array}$ & 20 & 20 & 20 & 20 & 20 & 20 \\
\hline $\begin{array}{l}\text { 'Daun limau purut' } \\
\text { (Citrus hystrix) }\end{array}$ & 10 & 10 & 10 & 10 & 10 & 10 \\
\hline $\begin{array}{l}\text { 'Pegaga' } \\
\text { (Centella asiatica L) }\end{array}$ & 60 & 60 & 60 & 60 & 60 & 60 \\
\hline
\end{tabular}

mins. The homogenates were kept at $4^{\circ} \mathrm{C}$ for $1 \mathrm{hr}$ and then centrifuged at $4000 \mathrm{rpm}$ for $10 \mathrm{mins}$. The supernatants were recovered and the residue was further washed with $40 \mathrm{~mL}$ of acetone: water $(70: 30, \mathrm{v} / \mathrm{v})$ and centrifuged. The resulting supernatants were combined and stored at $-20^{\circ} \mathrm{C}$.

\subsection{Analysis of antioxidant properties}

The total phenolic content of HS extracts was determined using Folin-Ciocalteau method (Barros et al., 2007). The total phenolic content was then expressed as $\mathrm{mg}$ gallic acid equivalent (mg GAE/g extract). Estimation of the phenolic compounds was carried out in triplicate. The analysis was conducted at the 0 -month of storage and the 6-month of storage.

The antioxidant activity assay was determined based on the antioxidant ability to inhibit the 2,2'-azinobis (3ethylbenzthiazoline)-6-sulfonic acid or ABTS free radical (ABTS + ) and compare the results with a reference standard (ascorbic acid) (Re et al., 1999) as well as by the Ferric Reducing Method (Oyaizu, 1986).
All samples were analyzed in triplicates.

\subsection{Statistical analysis}

All analysis was performed in triplicate and averaged. Analysis of Variance (ANOVA) was performed using SPSS V. 18 (SPSS Inc., Chicago, IL, USA) and mean values were statistically different at $\mathrm{P}<0.05$. The significantly different results were further separated using the Duncan Multiple Range Test (SPSS Inc., Chicago, IL, USA). Significance level was defined using $\mathrm{p}<0.05$.

\section{Results and discussion}

\subsection{Total phenolic content of herbal seasoning}

Phenol compounds are substances found naturally in legumes, vegetables, herbs, fruits, nuts, seeds and flowers which are part of human nutrition. Moreover, phenolic compounds exhibit an array of biological functions such as anti-carcinogenic, antiviral, antibacterial, antithrombotic, hepatoprotective, 
antiallergic, anti-inflammatory, and vasodilatory functions (Soobrattee et al., 2005). Phenols are strong antioxidants and most abundant compounds occurred in nature. They are antioxidant that responsible for free radical terminators and as free radical scavenging activities in many plants (Pourmorad et al., 2006).

The total phenolic contents (TPC) for the HS added with PSC powder are shown in Figure 1. At 0 month of storage, the methanolic extracts from the six treatments of HS ranged from $1000.36 \pm 0.32$ to $1823.84 \pm 0.84 \mathrm{mg}$ $\mathrm{GAE} / \mathrm{g}$ extract. The highest amount of TPC was found in HS (F) $(1823.84 \pm 0.84 \mathrm{mg} \mathrm{GAE} / \mathrm{g})$. The lowest of TPC was recorded in the control treatment HS (A) (1000.36 $\pm 0.32 \mathrm{mg} \mathrm{GAE} / \mathrm{g})$. Meanwhile, HS (E) showed the second higher of TPC (1462.30 $\pm 0.75 \mathrm{mg} \mathrm{GAE} / \mathrm{g})$. Generally, the TPC increased proportionally to the level of PSC powder added to HS. Figure 1 also shows the TPC of HS stored for 6 months. HS (A) showed the lowest content of TPC $(649.23 \pm 0.42 \mathrm{mg}$ GAE/g) Meanwhile, HS (F) recorded the highest TPC at the 6month of storage which significantly higher $(p<0.05)$ compared to other treatments $(1539.23 \pm 0.61 \mathrm{mg}$ GAE/ g). HS (D) and HS (E) showed no significant differences ( $>0.05$ ) which were $831.54 \pm 0.55 \mathrm{mg} \mathrm{GAE} / \mathrm{g}$ and $846.92 \pm 0.45 \mathrm{mg} \mathrm{GAE} / \mathrm{g}$, respectively. Meanwhile, both HS (C) and HS (B) also show no significant different ( $>0.05)$ during storage. The addition of the different level of PSC powder was speculated to influence the TPC content in the HS. The addition of PSC powder to replace CMP may influence the presence of bioactive compounds. In such case, the fat content of the product was reduced since the introduction of PSC powder. More interestingly, the total dietary fibre also has increased drastically. Therefore, PSC powder has contributed to the antioxidant properties of the products (data not shown).

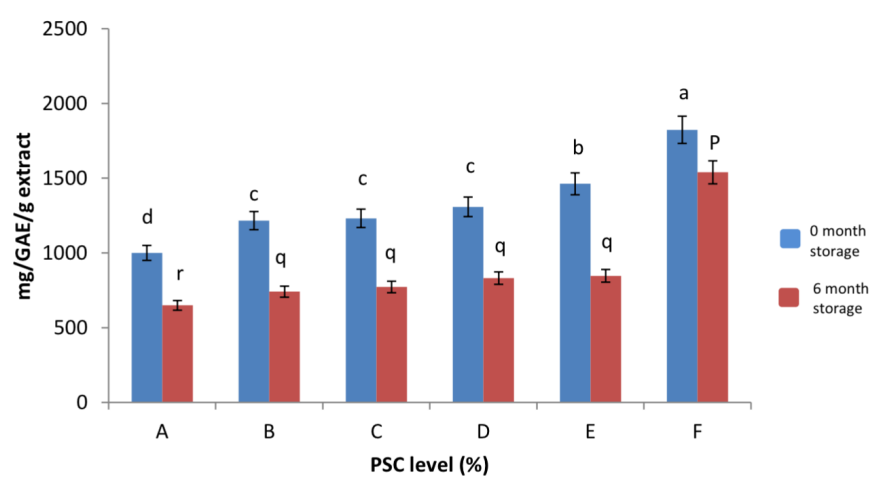

Figure 1. Total Phenolic Content of HS added with PSC powder (0 month and 6 month). Bars with different letters are statistically different $(\mathrm{P}<0.05)$. A $=0 \%$ PSC, $\mathrm{B}=20 \%$ PSC, C $=40 \% \mathrm{PSC}, \mathrm{D}=60 \% \mathrm{PSC}, \mathrm{E}=80 \% \mathrm{PSC}, \mathrm{F}=100 \% \mathrm{PSC}$

Generally, the TPC values in most cases have a coherent relationship with antioxidant capacity values obtained in other assays (Smolskaite et al., 2015). Interestingly, the natural antioxidant can be obtained in oyster mushrooms. Furthermore, the presence of phenolic compounds is the main characteristics of their antioxidant activity (Reis et al., 2012). The reduction of TPC at the 6-month of storage might be due to the instability of other antioxidant compounds, such as carotenoids and phenols. It has been reported that other antioxidants, such as ascorbic acid, $\beta$-carotene and lycopene are only found in small or vestigial amounts (Barros et al., 2007). Moreover, the use of plants containing antioxidants possibly can avoid the use of preservatives in food products.

Thermal processing commonly applied to extend the shelf life of food products. Due to the thermal processing, natural nutrients and bioactive compounds could be significantly lost since they are relatively unstable to heat. On the other hand, many recent findings have shown that thermally processed foods such as fruits and vegetables underwent various chemical changes during heat treatments (Dewanto et al., 2002). However, phenolic compounds easily become non-antioxidative and relatively unstable under heating thus, the heat used in the cooking procedure could destroy the structures of polyphenols and causes a decrease in their antioxidant activity (Yen and Hung, 2000). The reduction of TPC possibly related to the oxidation process occur in the product during shelf life study. Thermal treatment not only results in a decrease in the total polyphenol content but also changes their structure, which affects their antioxidant activity. The decrease in the antioxidant activity of cooked samples might have resulted in the destruction of phenolic hydroxyl groups due to high heat temperature.

\subsection{ABTS free radical scavenging activities of herbal Seasoning}

The antioxidant capacity of HS added with PSC powder as measured using the $\mathrm{ABTS}^{+}$free radical scavenging method is shown in Figure 2. HS extracts had showed the increasing percentage of inhibition in parallel with the increment level of PSC powder in the products. At the 0-month of storage, the highest scavenging inhibition was found in HS (F) with $100 \%$ substitution with PSC powder (71\%). The ability of HS (F) to scavenge ABTS + could also show its inhibition towards the formation of ABTS+. HS (E) was found to be 68.80 $\%$ at $1 \mathrm{mg} / \mathrm{mL}$ but was significantly different $(\mathrm{p}>0.05)$ with other samples. In addition, the percentage of inhibition of HS (B)-HS (D) was ranging from $49 \%$ to $53 \%$. The lowest scavenging capacity was observed in control extract $(46.7 \%)$. These results indicated that antioxidant compounds of PSC powder present in HS were able to donate of the hydrogen atom to ABTS free 
radical and consequently giving rise to its scavenging capacity.

Figure 2 also shows the ABTS scavenging ability of HS at the 6-month of storage. The percentage of the reduction in ABTS scavenging activity demonstrated in parallel to the addition of PSC in HS. The antioxidant capacity of HS added with PSC powder at the 6-month of storage ranged from $35 \%$ to $59 \%$. The highest scavenging was recorded in HS (F) $(59 \%)$ followed by HS (E) (52\%). Meanwhile, the control sample recorded the lowest inhibition capacity (35.5\%) and was not significantly different ( $p>0.05)$ with HS (B) $(37.14 \%)$. HS (C) and HS (D) did not significant different ( $p>0.05)$ which was $42.33 \%$ and $42.2 \%$, respectively.

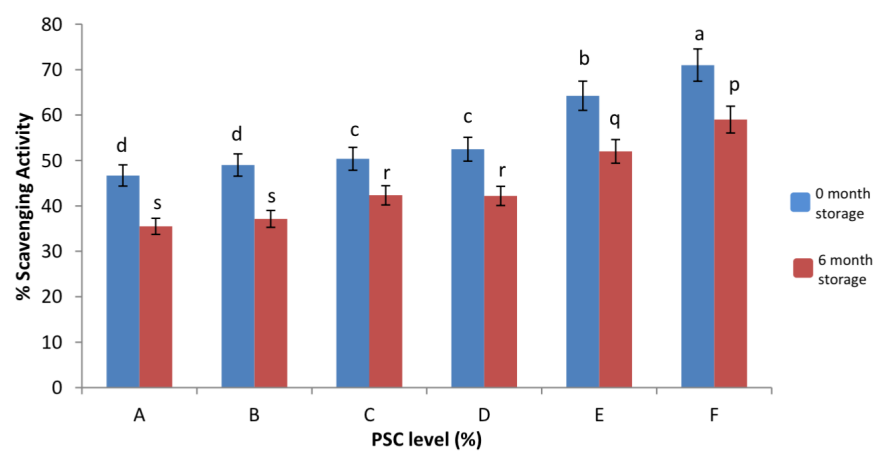

Figure 2. ABTS Scavenging Capacity of HS added with PSC powder (0 month and 6 month). Bars with different letters are statistically different $(\mathrm{P}<0.05)$. $\mathrm{A}=0 \% \mathrm{PSC}, \mathrm{B}=20 \% \mathrm{PSC}, \mathrm{C}$ $=40 \% \mathrm{PSC}, \mathrm{D}=60 \% \mathrm{PSC}, \mathrm{E}=80 \% \mathrm{PSC}, \mathrm{F}=100 \% \mathrm{PSC}$.

The mixture of herbal ingredients also influences the antioxidant activity of the extract. The percentage of radical scavenging of HS (F) was $71 \%$ at a concentration of $1 \mathrm{mg} / \mathrm{mL}$ for the initial month and was reduced to $59 \pm 0.25 \%$ after 6 months. These results indicated that the scavenging capacity was still high. It showed that PSC powder has the potential to become the natural antioxidant as it can scavenge the free radical in ABTS. It is known that ABTS is a protonated radical which is an important factor that contributes to the antioxidant. It has the maximum characteristic of proton radical scavenging at the absorbance of $734 \mathrm{~nm}$ and decreases with the scavenging of proton radicals (Mathew and Abraham, 2006). Working solutions of ABTS are required to be kept for $12 \mathrm{hrs}$ in the dark for the purpose to generate free radicals from the ABTS salt and then was used within 4 hrs (Arnao et al., 2001). The reaction between ABTS and potassium persulphate generates the blue and green ABTS radical cation (Mathew and Abraham, 2006).

HS extracts were added when stable absorbance was achieved, then the scavenging ability measured in terms of decolourization at $734 \mathrm{~nm}$. On the other aspect, the HS extract reacts with ABTS solution might have been different because the ABTS working solution was not always the same age. Therefore, the usage of the correct working solutions must always be in priority. Many factors such as the solubility of the extract, stereoselectivity of the radicals, polarity of the solvent and bioactive compounds, have been found to influence the extract to react and also quench different radicals. Our present findings displayed that the investigated formulation was a potent ABTS+ radical scavenger. The plant extract showed the capability to scavenge ABTS. Thus, the methanolic extract of the HS showed effective scavengers of the ABTS radical.

Antioxidant activities are normally directly increased proportionally to the polyphenol content. This activity is believed to be mainly due to their redox properties (Zheng and Wang, 2001). This concept is supported by a positive relationship of total phenols and antioxidant activity which becomes the trend in many plant species. Our findings showed that the methanolic extract of HS added with PSC powder given the potent scavenging activity since the increased antioxidant capacity which was compared to that of the standard antioxidant gallic acid. On the other hand, free-radical scavenging activities are related to the total phenol content in many plants (Pourmorad et al., 2006; Adedapo et al., 2008).

Many antioxidant compounds are mainly present as a covalently bound form with insoluble polymers. Therefore, it is suggested that heat treatment might disrupt the cell wall and liberate antioxidant compounds from an insoluble portion of mushroom, which, in turn, increases the pool of bioaccessible antioxidant compounds. Another reason for the improved antioxidant activity could be due to the formation of novel compounds having antioxidant activities during heat treatment or thermal processing (Choi et al., 2006).

\subsection{Ferric reducing antioxidant power of herbal seasoning}

The results of the reducing power assay of HS added with PSC powder are summarized in Figure 3. Higher absorbance indicates a higher reducing power. The reducing power of the methanolic extract of HS was found to steadily increase in direct proportion to the increasing concentration of the extract. HS (F) showed the highest reducing power $(60.52 \mathrm{mg} \mathrm{AAE} / \mathrm{g})$, followed by HS (E) (50.96 mg AAE/g). Meanwhile, HS (D), HS (C) and HS (B) showed reducing power of $46.28 \mathrm{mg}$ $\mathrm{AAE} / \mathrm{g}, 46.19 \mathrm{mg} \mathrm{AAE} / \mathrm{g}$ and $44.73 \mathrm{mg} \mathrm{AAE} / \mathrm{g}$, respectively. On the other hand, Control treatment without PSC powder (23.57 mg AAE/g extract) had the lowest reducing power and significantly different $(p<0.05)$ among all six HS formulations. In this assay, the test solution colour change from yellow to green 
depending on the reducing power of the extracts which play an important role as an indicator of the potential antioxidant activity. The reduction of the $\mathrm{Fe}^{3+} /$ ferricyanide complex to ferrous form in the test solution shows the presence of the reductant in the extracts (Chua et al., 2008).

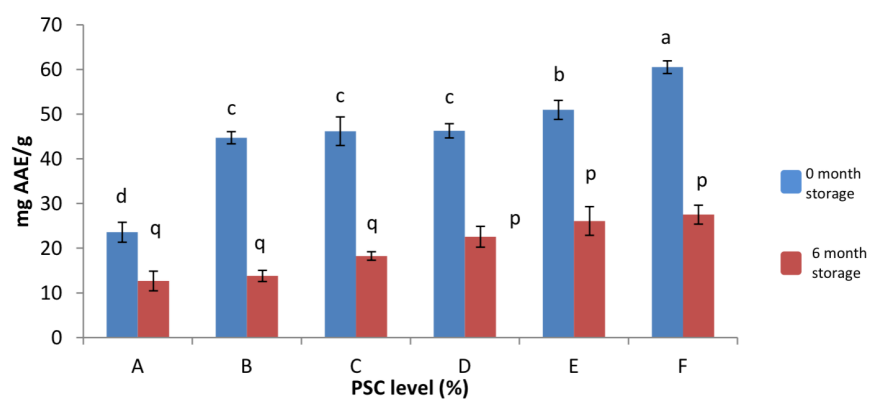

Figure 3. Reducing Power of HS added with PSC powder (0 month and 6 month). Bars with different letters are statistically different $(\mathrm{P}<0.05)$. $\mathrm{A}=0 \% \mathrm{PSC}, \mathrm{B}=20 \% \mathrm{PSC}, \mathrm{C}$ $=40 \% \mathrm{PSC}, \mathrm{D}=60 \% \mathrm{PSC}, \mathrm{E}=80 \% \mathrm{PSC}, \mathrm{F}=100 \% \mathrm{PSC}$.

The reducing power of the 6-month of storage recorded higher reducing power in line with the content of PSC powder in the HS formulations. The reducing power of the 6-month of storage ranged from 12.66 to $27.51 \mathrm{mg} \mathrm{AAE} / \mathrm{g}$ extract. The 6-month of storage of HS (B) - HS (F) showed a 60\% reduction which showed the reducing power ranging from $13.72 \mathrm{mg} \mathrm{AAE} / \mathrm{g}$ extract to $27.51 \mathrm{mg} \mathrm{AAE} / \mathrm{g}$ extract. However, HS (F) (27.51 mg AAE/g) were not significantly different $(p>0.05)$ with HS (E) (26.10 mg AAE/g extract). On the other hand, the control sample (12.66 mg AAE/g extract) were not significantly different from HS (B)(13.79 mg AAE/g extract)

\section{Conclusion}

The study showed that examined PSC powder possess good antioxidant activity and in which the phenolic substances contribute to this activity. Antioxidant activities showed that HS (F) demonstrated the highest ABTS scavenging activities and was parallel to the PSC powder added in the formulations. During storage, antioxidant activity was observed to decrease in all cases. Moreover, thermal treatment not only resulted in a decrease in the total polyphenol content but also changed their structure, which affected their antioxidant activity. Thus, it is concluded that PSC powder represents a rich source of phenolic compounds and might serve as possible ingredients in foods and could help in reducing the oxidative damage. However, in vivo antioxidant assays are necessary to confirm the potential use of these species. On the other hand, more studies could be explored to identify which phenolic compounds are responsible for the antioxidant activity of the species.

\section{Conflict of interest}

The authors declare no conflict of interest.

\section{Acknowledgements}

The authors would like to thanks MARDI and USM for funding and sincere appreciation to all the staffs including Mr Shazwan Zain, Mrs Nurhanan, Mrs Aishah from Nutrition and Food Preparation laboratory in the School of Health Sciences, Health Campus, USM for their help and guidance towards the success of this research.

\section{References}

Adedapo, A.A., Jimoh, F.O., Koduru, S., Afolayan, A.J. and Masika, P.J. (2008). Antibacterial and antioxidant properties of the methanol extracts of the leaves and stems of Calpurnia aurea. BMC Complementary Medicine and Therapies, 8, 53. https://doi.org/10.1186/1472-6882-8-53

Aishah, M.S. and Wan Rosli, W.I. (2013). The effect of addition of oyster mushroom (Pleurotus sajor-caju) on nutrient composition and sensory acceptation of selected wheat and rice based products. International Food Research Journal, 20(1), 183-188.

Arnao, M.B., Cano, A. and Acosta, M. (2001). The hydrophilic and lipophilic contribution to total antioxidant activity. Food Chemistry, 73(2), 239244. https://doi.org/10.1016/S0308-8146(00)00324-1

Barros, L., Cruz, T., Baptista, P., Estevinho, L. and Ferreira, I. (2008). Wild and commercial mushrooms as source of nutrients and nutraceuticals. Food and Chemical Toxicology, 46(8), 2742-2747. https:// doi.org/10.1016/j.fct.2008.04.030

Barros, L., Ferreira, M.J., Queiros, B., Ferreira, I.C.F.R. and Baptista, P. (2007). Total phenols, ascorbic acid, [beta]-carotene and lycopene in Portuguese wild edible mushrooms and their antioxidant activities. Food Chemistry, 103(2), 413-419. https:// doi.org/10.1016/j.foodchem.2006.07.038

Berk, Z. (2013). Food Process Engineering and Technology. $2^{\text {nd }}$ ed. USA: Elsevier Science Publishing Co Inc.

Bottani, E., Montanari, R., Vignali, G. and Guerra, L. (2011). A survey on packaging materials and technologies for commercial food products. International Journal of Food Science, 7(1), 12-14. https://doi.org/10.2202/1556-3758.1687

Caglarirmak, N. (2007). The nutrients of exotic mushrooms (Lentinula edodes and Pleurotus sp.) and an estimated approach to the volatile compounds. Food Chemistry, 105(3), 1188-1194. https:// 
doi.org/10.1016/j.foodchem.2007.02.021

Charalambous, G. (Ed.) (1993). The shelf life of fruits and vegetables, in shelf life studies of foods and beverages, chemical, biological, physical and nutritional aspects, p. 195. Amsterdam: Elsevier Science Publishers.

Choi, Y., Lee, S. M., Chun, J., Lee, H.B. and Lee, J. (2006). Influence of heat treatment on the antioxidant activities and polyphenolic compounds of Shiitake (Lentinusedodes) mushroom. Food Chemistry, 99(2), 381-387. https://doi.org/10.1016/ j.foodchem.2005.08.004

Chua M.T., Tung Y.T. and Chang S.T. (2008). Antioxidant activity of ethanolic extracts from the twigs of Cinnamomum osmophloeum. Bioresource Technology, 99(6), 1918-1925. https:// doi.org/10.1016/j.biortech.2007.03.020

Dewanto, V., Wu, X., Adom, K.K. and Liu, R.H. (2002). Thermal processing enhances the nutritional value of tomatoes by increasing total antioxidant activity. Journal of Agricultural and Food Chemistry, 50, 3010-3014. https://doi.org/10.1021/jf0115589

Halliwell, B. and Gutteridge, J.M.C. (1999). Free Radicals in Biology and Medicine. United Kingdom: Oxford University Press.

Kaur, C. and Kapoor H.C. (2001). Antioxidants in fruits and vegetables - the millennium's health.

International Journal of Food Science and Technology, 36(7), 703-725. https://doi.org/10.1046/ j.1365-2621.2001.00513.x

Klein, B.P. and Kurilich, A.C. (2000). Processing effects on dietary antioxidants from plant foods. HortScience, 35(4), 580-84. https:// doi.org/10.21273/HORTSCI.35.4.580

Kurtzman, R.H. (2005). Mushrooms: sources of modern western medicines. Micologia Aplicada International, 17(2), 21-33.

Mahae, N. and Chaiseri, S. (2009). Antioxidant activities and antioxidative components in extracts of Alpinia galanga (L.) Sw. Kasetsart Journal: Natural Science, 43, 358-369.

Manzi, P., Gambelli, L., Marconi, S., Vivanti, V. and Pizzoferrato, L. (1999). Nutrients in edible mushrooms: an inter-species comparative study. Food Chemistry, 65(4), 477-482. https:// doi.org/10.1016/S0308-8146(98)00212-X

Mathew, S. and Abraham, T.E. (2006). In vitro antioxidant activity and scavenging effects of Cinnamomum verum leaf extract assayed by different methodologies. Food and Chemical Toxicology, 44(2), 198-206. https://doi.org/10.1016/ j.fct.2005.06.013
Mau, J.L., Lin, H.C. and Chen, C.C. (2002). Antioxidant properties of several medicinal mushrooms. Journal of Agricultural and Food Chemistry, 50(21), 60726077. https://doi.org/10.1021/jf0201273

Olajire, A.A. and Azeez, L. (2011). Total antioxidant activity, phenolic, flavonoid and ascorbic acid contents of Nigerian vegetables. African Journal of Food Science and Technology, 2(2), 022-029.

Oyaizu, M. (1986). Studies on products of the browning reaction. Antioxidative activities of browning reaction products prepared from glucosamine. Japanese Journal of Nutrition, 44(6), 307-315. https://doi.org/10.5264/eiyogakuzashi.44.307

Pourmorad, F., Hosseinimehr, S.J. and Shahabimajd, N. (2006). Antioxidant activity, phenol and flavonoid contents of some selected Iranian medicinal plants. African Journal of Biotechnology, 5(11), 1142-1145.

Reis, F.S., Barros, L., Martins, A. and Isabel Ferreira, C.F.R. (2012). Chemical composition and nutritional value of the most widely appreciated cultivated mushrooms: Aninter-species comparative study. Food and Chemical Toxicology, 50(2), 191-197. https://doi.org/10.1016/j.fct.2011.10.056

Silveira, M.L.L., Smiderle, F.R. and Agostini, F. (2015). Exopolysaccharide produced by Pleurotus sajorcaju: Its chemical structure and anti-inflammatory activity. International Journal of Biological Macromolecules, 75, 90-96. https://doi.org/10.1016/ j.ijbiomac.2015.01.023

Smolskaite, L., Venskutonis, P.R. and Talou, T. (2015). Comprehensive evaluation of antioxidant and antimicrobial properties of different mushroom species. LWT - Food Science and Technology, 60(1), 462-471. https://doi.org/10.1016/j.lwt.2014.08.007

Soobrattee, M.A., Neergheen, V.S., Luxi-mon-Ramma, A., Aruoma, O.I. and Bahorun, T. (2005). Phenolics as potential antioxidant therapeutic agents: mechanism and actions. Mutation Research, 579, 200-213. https://doi.org/10.1016/ j.mrfmmm.2005.03.023

Statistical Package for Social Science (SPSS) version 18, 2010. United States of America: SPSS Inc. Chicago

Turkoglu, A., Duru, M.E. and Mercan, N. (2007). Antioxidant and antimicrobial activity of Russula delica Fr: an edible wild mushroom. Eurasian Journal of Analytical Chemistry, 2(1), 54-67. https:// doi.org/10.12973/ejac/78055

Wan Rosli, W.I., Nurhanan, A.R. and Aishah, M.S. (2012). Effect of partial replacement of wheat flour with oyster mushroom (Pleurotus sajor-caju) powder on nutritional composition and sensory properties of butter biscuit. Sains Malaysiana, 41 
(12), 1565-1570.

Wang, Y., and Xu, B. (2014). Distribution of antioxidant activities and total phenolic contents in acetone, ethanol, water and hot water extracts from 20 edible mushrooms via sequential extraction. Austin Journal of Nutrition and Food Sciences, 2(1), 1-5.

Wasser, S.P. (2010). Medicinal mushroom science: history, current status, future trends, and unsolved problems. International Journal of Medicinal Mushrooms, 12(1), 1-16. https://doi.org/10.1615/ IntJMedMushr.v12.i1.10

Yen, G.C. and Hung, C.Y. (2000). Effects of alkaline and heat treatment on antioxidative activity and total phenolics of extracts from Hsian-tsao (Mesona procumbens Hemsl.). Food Research International, 33(6), 487-492. https://doi.org/10.1016/S0963-9969 (00)00073-9

Zheng, W. and Wang, S.Y. (2001). Antioxidant activity and phenolic compounds in selected herbs. Journal of Agricultural and Food Chemistry, 49, 5165-5170. https://doi.org/10.1021/jf010697n 